\title{
Competitive Swedish Composite Bridges
}

\author{
Peter Collin \\ Prof. Composite Structures \\ LTU/Scandiaconsult \\ Luleå, Sweden \\ Peter Collin, born 1960, \\ presented his $\mathrm{PhD}$ thesis 1992 , \\ concerning the stability of steel \\ frames. He has since been \\ working with design and \\ development of steel- and \\ composite bridges.
}

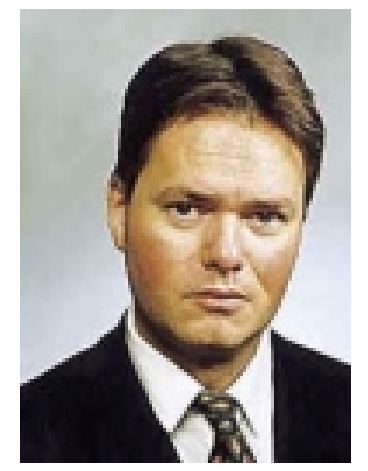

\author{
Tore Lundmark \\ Chief Designer \\ Scandiaconsult \\ Luleå,Sweden
}

Tore Lundmark, born 1943, received his civil engineering degree from the Chalmers University of Technology. He has since been working with the design of steel structures, including composite bridges.

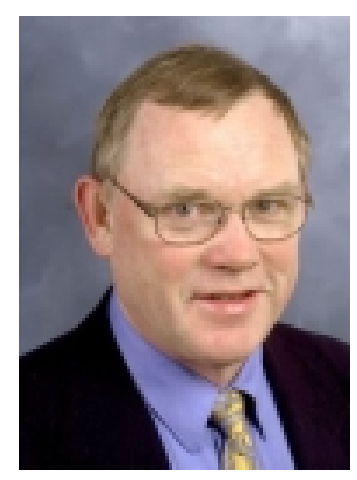

\section{Summary}

During the 1990's, composite steel and concrete bridges took over an increasing portion of the market. The purpose of this article is to highlight current developments in the field of girder bridges, which account for the majority of the composite bridges.

Keywords: Composite bridges, high strength steel, hybrid girders, prefabricated decks, integral abutments.

\section{Introduction}

It is often necessary when constructing concrete bridges to elevate the structure from ground level. Building steel bridges with a composite concrete deck is a means of circumventing this step. Indeed, the steel girders' ability to support formwork, reinforcement and the deck concrete has greatly contributed to the increasing popularity of composite bridges, along with the reduced construction time compared to concrete bridges.

In reality, the deck helps the upper flange of the cross-section, so that upper flange stresses are almost restricted to those that arise before the concrete has set. Over interior supports the concrete is considered to be cracked, implying that the reinforcement alone contributes to the moment capacity of the composite cross-section. It follows that the upper flange over mid support features basically the same dimensions as the lower flange.

For a bridge with a width of $7 \mathrm{~m}$, i.e. 2 lanes, the girders are typically spaced $4 \mathrm{~m}$.

The cross-section area of the roadway is $2 \mathrm{~m}^{2}$ and the longitudinal reinforcement constitutes approximately $1 \%$ of this area, although in practice this figure is reduced to $0.5 \%$ for longer spans. Among others, this figure is determined by the calculated crack width at supports, which under normal circumstances may not exceed the usability limit of $0.3 \mathrm{~mm}$. In the transverse direction, the amount of reinforcement is typically $1.5 \%$, or $120 \mathrm{~kg} / \mathrm{m}^{3}$. 


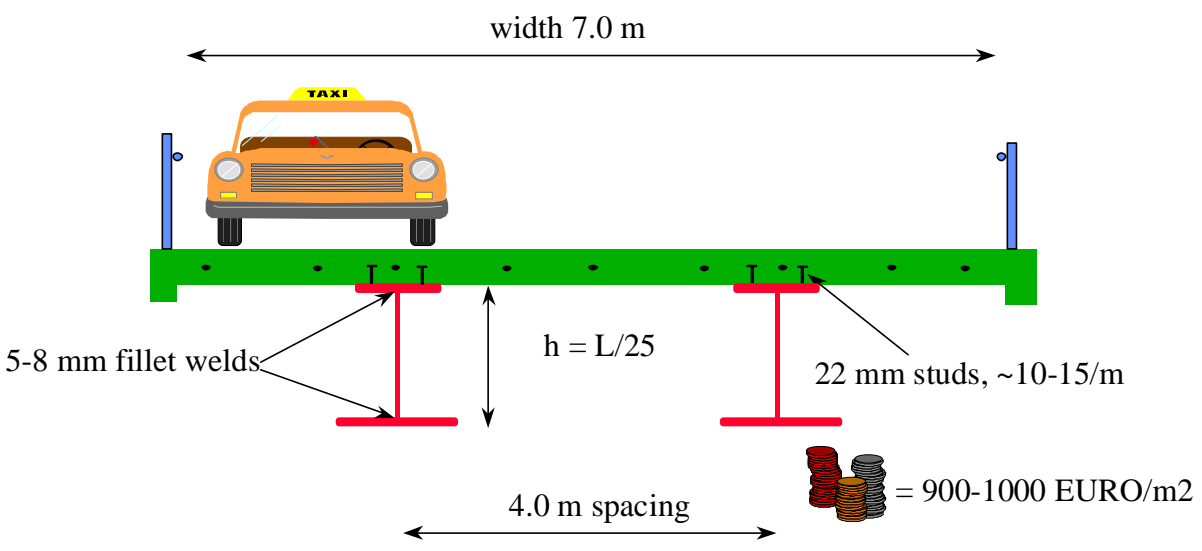

Fig. 1 Cross-section of a typical composite bridge

The cost per sq. $m$ of the substructure and the steel superstructure usually lie around EURO 300 each [1], [2]. Of course, this amount varies with span widths, foundation conditions etc.

Table 1 Typical cost allocation for a Swedish composite bridge

\begin{tabular}{|l|r|}
\hline Typical cost for a composite bridge & EURO/m \\
\hline Substructure & 300 \\
\hline Steel superstructure & 300 \\
\hline Concrete deck & 150 \\
\hline Pavement, parapets etc. & 250 \\
\hline Total & Ca 1000 \\
\hline
\end{tabular}

The quoted steel price consists of material costs to $1 / 4$; the rest is for fabrication of girders, corrosion protection, transport, launching, joints, control etc.

\section{Lovelier Bridges}

In addition to sound technical qualities such as design life, bearing strength and easy maintenance, the steel bridge also offers great aesthetic value for money. The option for the owner to choose the color of the structure undeniably provides a new range of possibilities.

Beauty is in the eye of the beholder, as the saying goes, and clever choices of bridge color and form can yield the following success stories:

In 1993, the Swedish Steel Construction Institute published "Steel Bridges", proposing means of making existing and planned bridges more aesthetically pleasing by means of well-planned steel alternatives. One of the most effective ideas involved replacing the usual chamfered concrete 3 span struts with a composite arch for spanning e.g. motorways.

The architects leapt at the chance to try this concept in the bridges of the Höga Kusten project. 


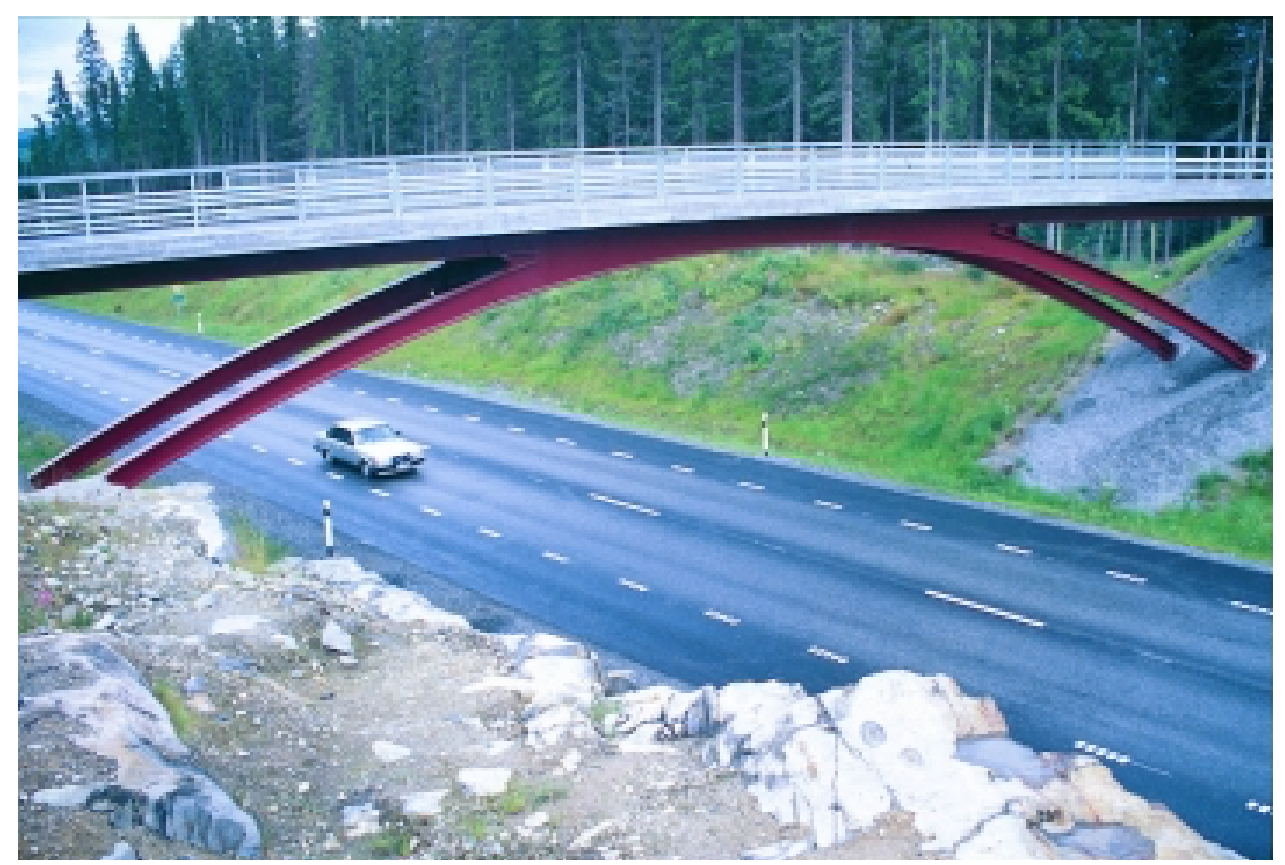

Fig. 2 Bridge over E4 at Höga Kusten

The arch legs carry the load from the center of the bridge, and although they might as well be straight from a static point of view, the curved arch structure undeniably lends a more appealing impression, which is enhanced further by the slender dimensions of the steelwork.

The Höga Kusten bridges across Majorsviken and Storsjön are other examples where adopting a parabolic shape has beautified the structures. By using haunched girders, the lower flange comes to resemble the underside of a vaulted bridge, in spite of the straight stretches in the middle of the spans. Here, the height of the steel structure is $3.1 \mathrm{~m}$ at supports and $1.9 \mathrm{~m}$ at midspan. Major effort has also been invested in the design of the concrete supports.

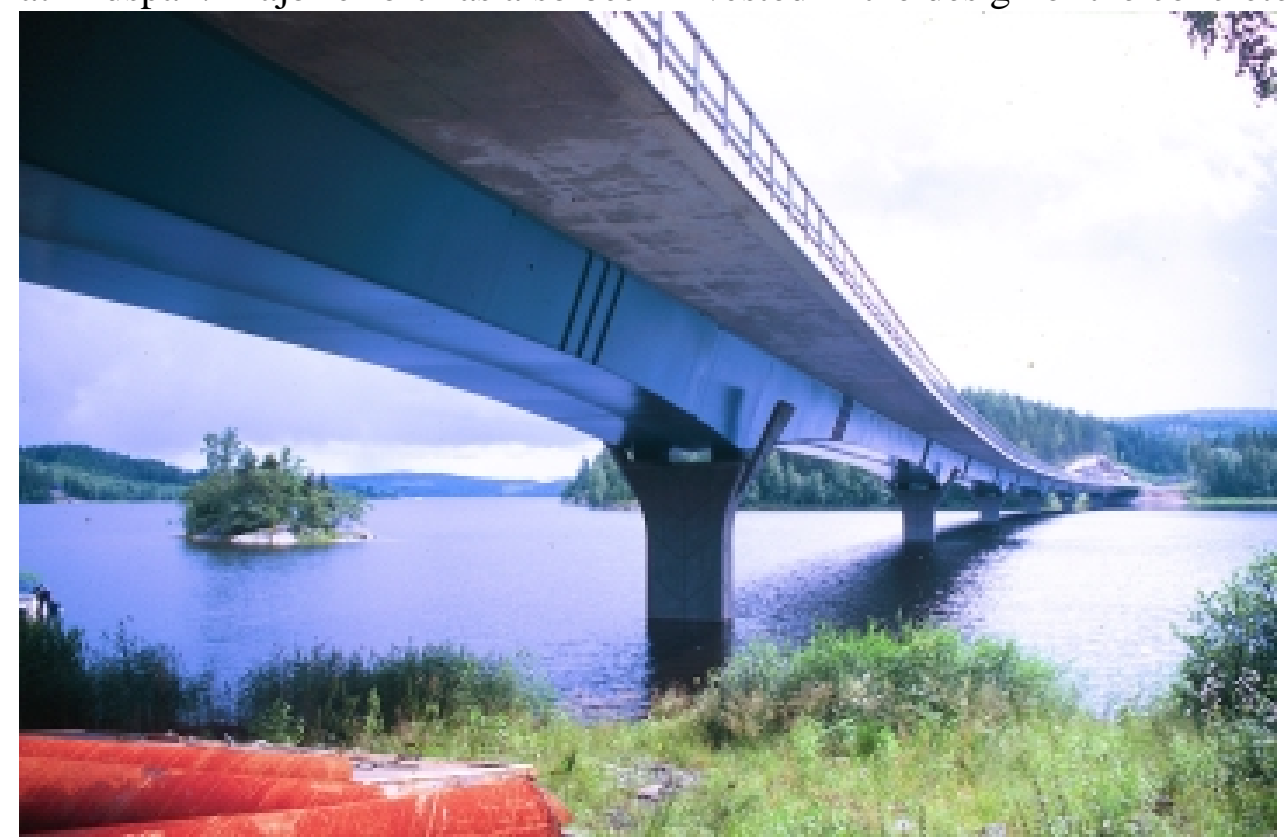

Fig. 3 Box Girder Bridge over Majorsviken 
The final case concerns the $1500 \mathrm{~m}$ long bridge over Vallsundet in Sweden, connecting the island Frösön with the mainland. This bridge was designed as an unhaunched box, is mainly characterized by the soft vertical radius and the triangular supports under the highest point. In addition to being aesthetically pleasing, they facilitated the introduction of an extra wide span across the navigation channel.

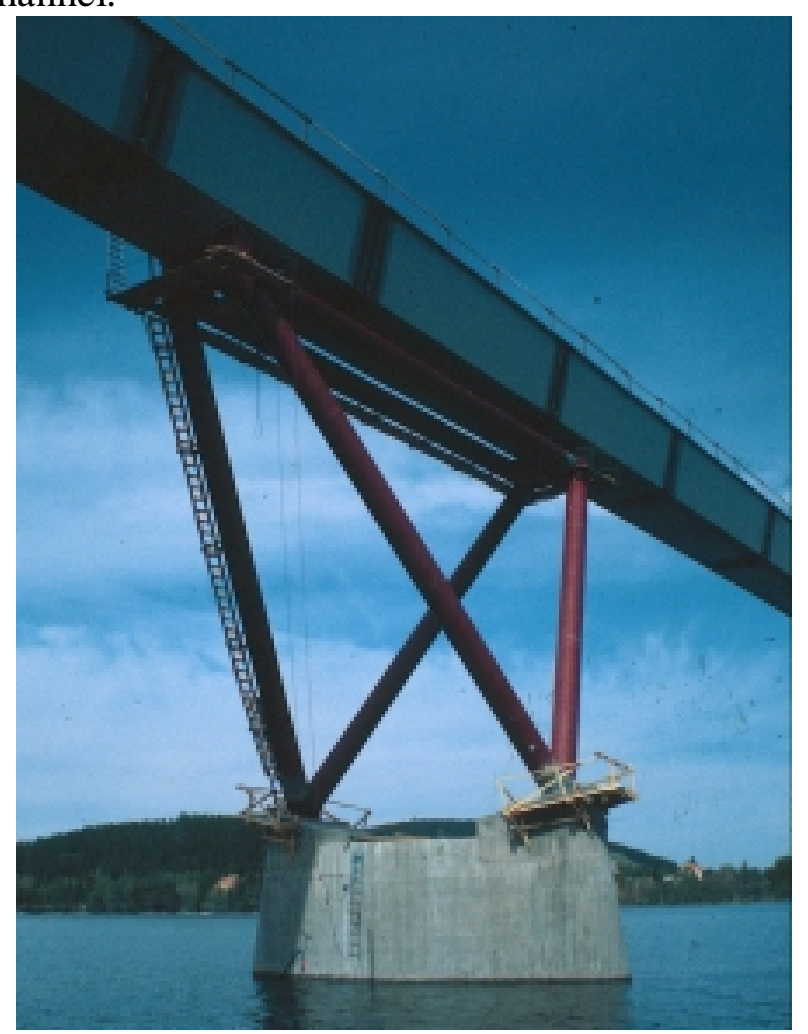

Fig. 4 Triangular support of the bridge across Vallsundet during launching

\section{Stronger Steel}

The $20^{\text {th }}$ century has witnessed the steel producers' quest for increasingly durable types of steel. The main reason for this is that the steel mills can deliver higher strength at a low cost and without inferior toughness.

In step with the steel mills becoming more skilled at manufacturing Termomechanically rolled steel, where both the microstructure and the strength are determined by the temperature of the ultimate rolling, they have been introduced into the Swedish bridges. Today, the three following grades are commonly used in bridge main girders:

- $\mathrm{S} 355 \mathrm{~J} 2 \mathrm{G} 3$ or $\mathrm{S} 355 \mathrm{~N}$

- S420M Termomechanically rolled fine-grained steel

- S460M Termomechanically rolled fine-grained steel

The steel grades are listed in the European Steel Standards EN10025 and EN10113, which are published in Sweden using the Swedish National Application Document (NAD).

It is common practice to mix these grades within a cross section, with the strongest in the flanges and the weaker grade in the web. These cross-sections of mixed type are known as 
"hybrid girders", and are regulated in the Swedish Bridge Code BRO94 [3]. This document states that the strength of the flanges may not exceed that of the webs by more than $50 \%$. Furthermore, when the web is reduced with respect to buckling of normal stresses, the effective web thickness is calculated based on the strength of the flange, not the web itself.

In 1995, a bridge with Extra High Strength Steel in the lower flange was erected in Mittådalen [4]. The selected steel grade is S690 (WELDOX 700), which is included in the European standard EN 10137. In the figure below, concrete deck elements are mounted on the steel girders.

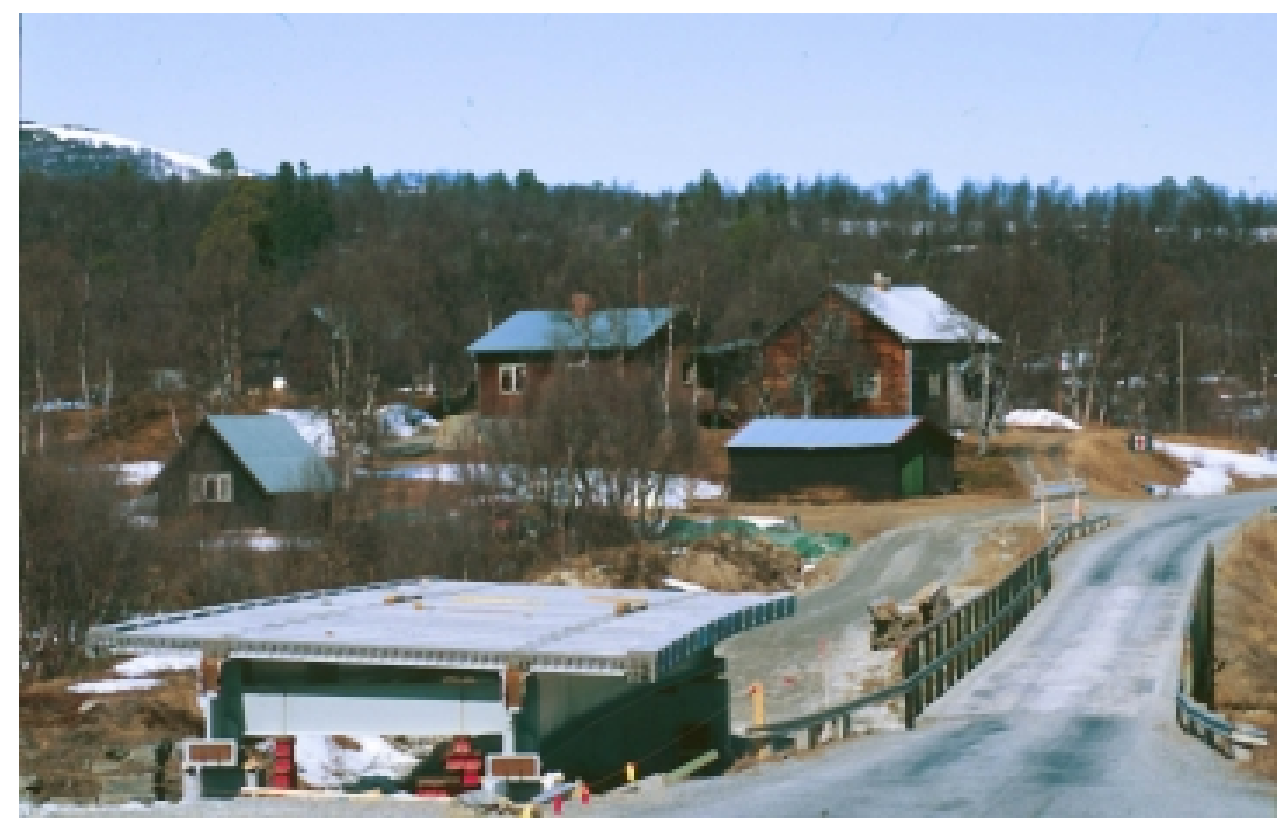

Fig. 5 Bridge Z1207 in Mittådalen

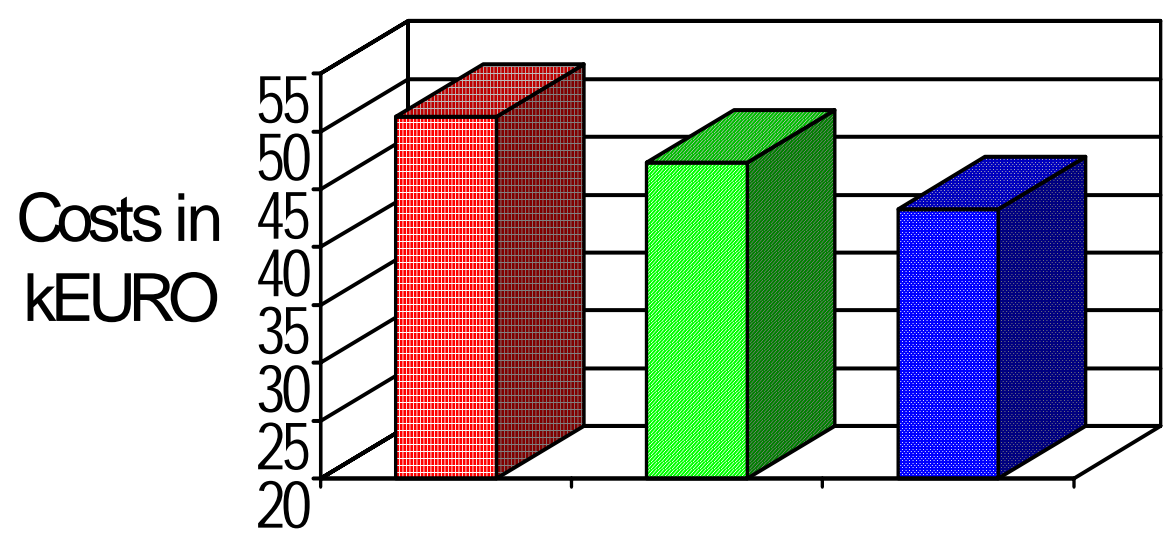

Fig. 6 Cost savings yielded by three mixes of material; S355 all over the cross section; S460 in only the bottom flange and to the right; S460 in the web and top flange, mixed with S690 in the bottom flange.

In this case, the steel contractors had three alternatives to evaluate. It was calculated that the solution adopting S690 in the lower flange and S460 in the web and upper flange proved the 
least costly choice. Using S690 in the upper flange is less cost-effective, as it is often submitted to buckling/lateral-torsional buckling during the casting cycle.

In the case of continuous bridges, the same applies to mid span regions, whereas the opposite is true for the support area, i.e. tensile force in the upper and compression in the lower flange. The latter is determined mainly by lateral-torsional buckling, implying that a transition from e.g. S460 to $S 690$ necessitates a reduction in the width/thickness ratio of the flange to reach the fully elastic moment. This slenderer flange in turn requires a substantial reduction in the distance between the cross bracings, in order to avoid lateral-torsional buckling of the lower flange. Contrarily, the upper flange is subject to tensile forces at supports; however, using steel grade S690 would cause excessive reinforcement stresses as well as cracks in the concrete deck.

One reason for the limited use of this concept for simply supported bridges and the midspan girders of continuous bridges is the longer delivery time for toughened steel plate in comparison to Termomechanically rolled steel. Indeed, considering the narrow time margins where oftentimes both the order of materials and earthworks are carried out without ownerapproved documentation, increased delivery times is not an option. An increased use of S690 in bridges would thus require an improved delivery stand-by time from the steel mills. At a glance, the short time spans available today for executing the projects might appear to be the result of bad planning by the Swedish National Road Administration, but are also intimately connected to insecurity regarding funding and prioritizing from the Government.

\section{Rational Methods on Site}

In order to achieve rational construction routines, a vital criterion is the uncomplicated placing of the steel girders. For multi-span bridges, it is often rational to launch the girders on roller bearings of steel or Teflon bearings. As the end spans frequently are up to $20 \%$ shorter than the middle spans, this is achieved by means of a launching nose demonstrating at least $20 \%$ of the width of the midspan. This device has the following functions:

- Ensuring that mid-support is reached when a supporting girder cross-section is located precisely above a mid-support.

- Constructing the nose as a truss renders a substantially lower weight/m, thereby reducing the cantilever moment of the steel girders.

- By angling the underside of the nose upwards, compensation for vertical deformation at the cantilever tip is achieved, thereby launching the nose on to the bearings with an increasing support reaction. 


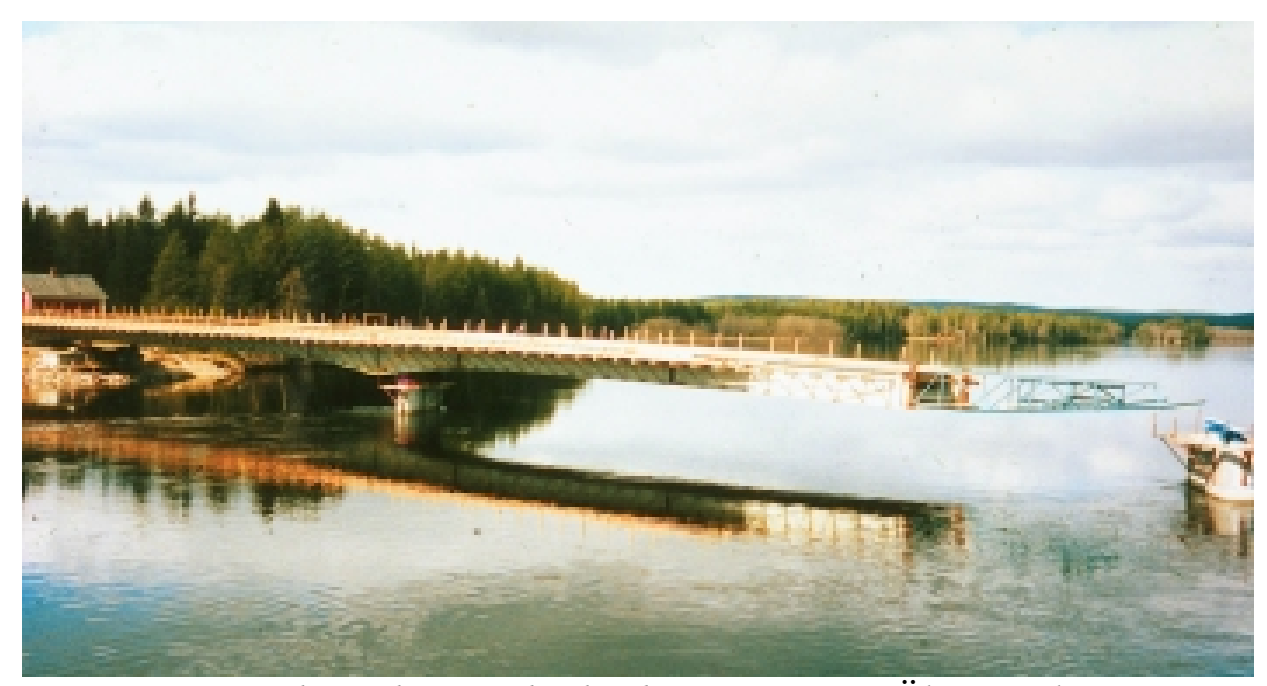

Figure 7. Launching the I girder bridge across Pite Älv at Böle

An alternative to launching is to lift the steel girders into place. The Sävarå Bridge, a box in a 54-m span, exemplifies this method. After being rolled out on the existing bridge, it was lifted to the new bridge location $15 \mathrm{~m}$ downstream using mobile cranes.

One of the advantages offered by composite bridges compared to concrete is that the girders can double as formwork for the roadway once they have been launched or lifted into place. Two common procedures include:

- Formwork casting is braced against the lower flanges of the steel girders. The formwork structure is held together by tie-rods threaded through predrilled holes in the web. However, a wide bridge deck or low-profile girders result in an undesirably flat angle at the truss form members.

- For composite boxes, the concrete is often cast between the webs by means of trapezoidprofiled sheeting. The sheeting is placed transversely across the bridge, mounted on trestles that are braced against the box floor. The roadway cantilevers are cast using a formwork bus, which is moved along rails placed on the upper flange. For shorter bridges, two castings per span is adequate (first at midspan, then at supports), and in the case of longer spans, two or more formwork buses can be used simultaneously. 


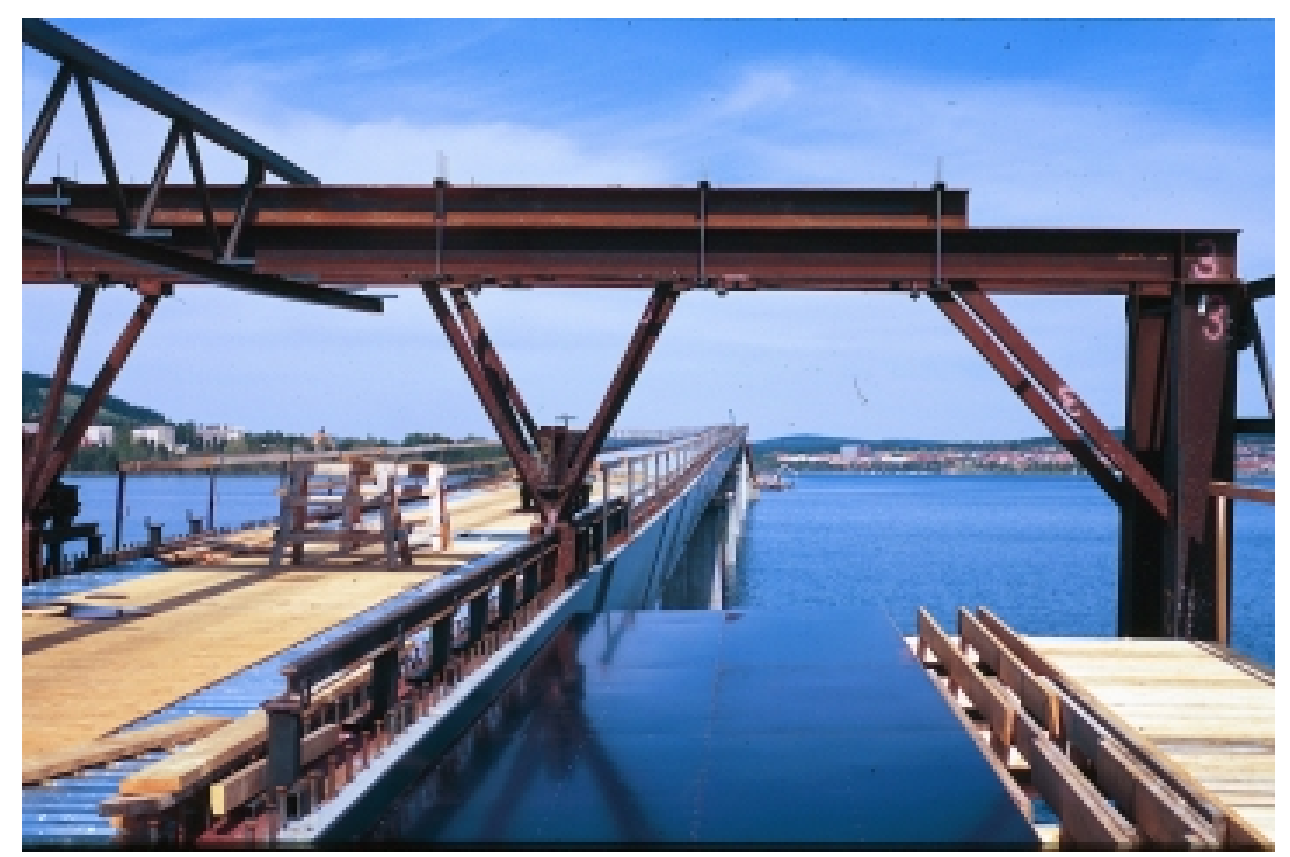

Fig. 8 Casting the roadway for a composite box using a form bus

\section{Shop-adapted Bridges and Documentation}

Adapting steel bridges to shop production is just as important as rational production methods on site. This renders a sound economy, i.e. true value for money. At this stage it is worth noting that the best economy is synonymous with the lowest steel volume during the tender phase. The following parameters shall also be taken into account:

- Minimizing the number of joints. Indeed, there have been examples of bridges with flange joints every second meter at supports in order to keep the amount of steel to a minimum. Obviously, the savings in material costs are rapidly consumed by the additional work involving cutting and butt welds in the flange; especially control of the latter!

- Designing production-friendly steel boxes by replacing box trusses with cold formed diaphragms in boxes, instead of rolled-profile trusses. Although this might generate a slightly elevated total weight, the production cost is kept at a minimum. The use of stiffeners in webs and flanges should also be kept to a minimum.

- Minimizing the number of transport units and thereby the number of joints carried out on site. A joint carried out in situ is more costly than one fabricated in a shop, due to additional paintwork, control and sensitivity to weather conditions.

- Not to vary plate thickness, rolled profiles etc. ad infinitum for time and availability reasons. Furthermore, calculations, drawings and shop handling become more expensive if e.g. all girders in a symmetrical multi-span bridge have different upper flanges due to the order of casting the concrete.

Producing production-friendly or shop-adapted documentation is often subject to discussion, also in contract negotiations between the contractor and the steel subcontractor as well as the designer. Considering that different shops have different preferences, it can be difficult to ascertain what is intended, especially since design works often commence before the steel contractor is appointed. One possibility to avoid this is to have the steel designer working directly for the steel contractor, which would also be an incitement to invest more in 
development schemes. It would also simplify work for the building contractor, who is seldom used to purchasing the major steel contracts that steel bridges often imply.

\section{Prefabricated Composite Bridges}

One step in the right direction towards an industrialized construction is to prefabricate not only the steel girders, but also the concrete road deck. By using steel girders with prefabricated roadways, the following advantages are gained [2]:

- A shorter construction time gives timesaving for the bridge users and in some cases a reduced need for costly by-pass roads.

- Reduced disturbance for the traffic below.

- Shorter construction time.

- Improved working environment with respect to the work with formwork, reinforcement and casting.

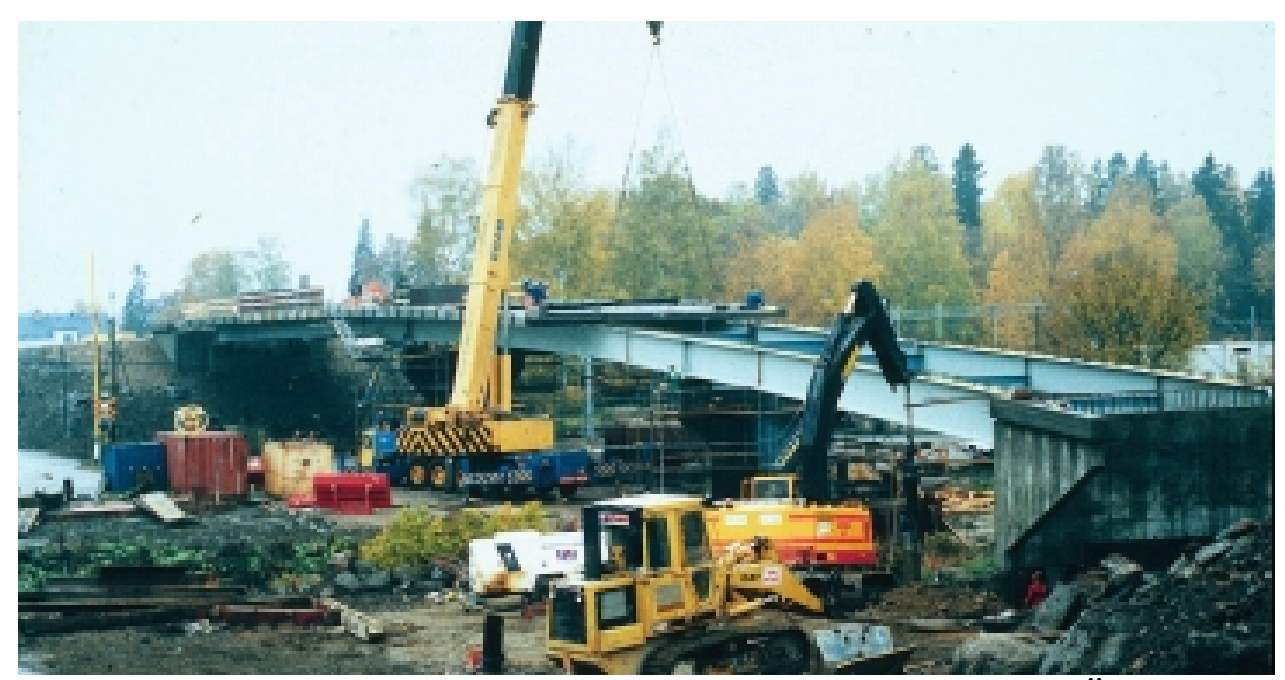

Fig. 9 Prefabricated composite bridge crossing the railroad at Örbyhus

A research project is underway at Luleå University of Technology's Division for Steel Structures in collaboration with Strängbetong and Scandiaconsult. The project is funded by the Swedish Construction Industry organisation for research and development, SBUF. Within the frames of this project, a new technology for dry joints between roadway elements has been developed. The Ph.D. student Anders Stoltz [5] tested a number of elements with regard to fatigue as well as the shear force capacity of the joints, and a pilot bridge based on these findings was built across Rokå River outside Piteå in 2000.

\section{Integral Abutments}

Expansion joints are a weak point in bridge structures and require costly maintenance. It is therefore natural to avoid them insofar as possible. Instead, continuous girders are selected in lieu of simply supported ones, and expansion joints are avoided. The prior has been common practice in Sweden for some time and the latter is used for shorter frame bridges.

Bridges with backwalls connected to the steel girders are cost effective compared to bridges with conventional abutments and transitional structures. The maximum length of end shield bridges is determined on a case to case basis by the owner Authority in question, and 
normally lies around $60 \mathrm{~m}$. However, bridges with the back walls connected directly to the girders require end supports and bearings.

In the United States, integral abutments are used in a more brazen way. The bridges are longer, up to $120 \mathrm{~m}$, and the foundation works are simplified. Piles are driven under the back wall, which is made shallower than in Sweden. Seen from a Swedish perspective, the problem is that a conventional elastic analysis fails to explain how the bridge works!

In order to develop the technology and adapt it to Swedish conditions, the Division of Steel Structures at Luleå University of Technology has managed a post-graduate project to this end in collaboration with Scandiaconsult and the contractor Skanska.

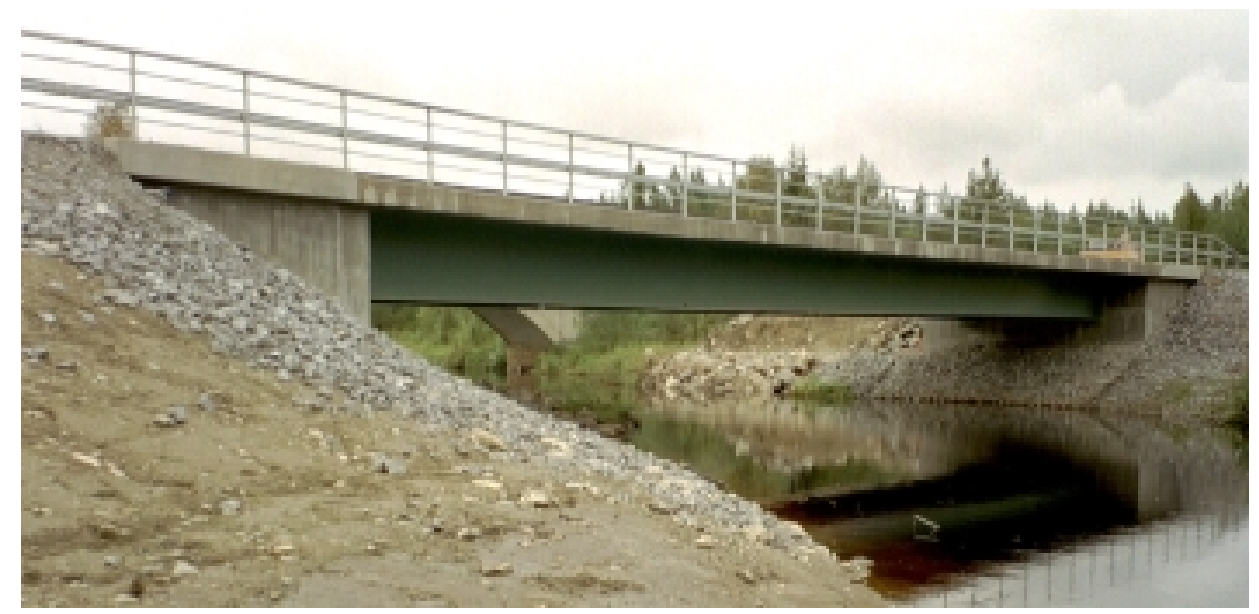

Fig.10 Bridge over Fjällån River

Within the boundaries of this project, Hans Petursson performed static testing of X-piles simulating both the normal forces of outer loading and an end displacement corresponding to the temperature fluctuations in a bridge, as well as comprehensive computer simulations [6]. Among others, the project resulted in the Swedish National Road Administration ordering a composite bridge adopting the new technology demonstrated in the project. The bridge spans the Fjällån River outside Dorotea, and the steel girders cast in the concrete back wall. Hopefully, the Swedish National Road Administration will start incorporating this concept directly in their basic design drawings.

\section{References}

[1] COLLIN P., "Some trends in Swedish Bridge Construction", International Conference on welded Structures, 2-3 September 1996, Budapest, Hungary, pp 163-172.

[2] COLLIN P. and JOHANSSON B., "Wettbewerbsfähige Brücken in Verbundbauweise", Stahlbau 68 (1999), Heft 11, pp 908-918.

[3] BRO94, Swedish Regulations for Bridges, Swedish National Road Administration, Borlänge, 1994(in Swedish).

[4] JOHANSSON B. and COLLIN P., "High Strength Steel- the Construction Material of the Future", International Steel Construction Conference, Delft, February 1999.

[5] STOLTZ A., "Effektivare samverkansbroar", Licentiate Thesis 2001:141, Luleå University of Technology, 2001(in Swedish). 
[6] PETURSSON H., “Broar med integrerade landfästen”, Licentiate Thesis 2000:32, Luleå University of Technology, 2000(in Swedish).

[7] GOURMELON J-P, "Trends and developments for steel and composite bridges in France", International Conference on Welded Structures, 2-3 September 1996, Budapest, Hungary, pp 127-161.

[8] NAKAMURA S. et al, "New Technologies of Steel/Concrete Composite Bridges, Journal of Constructional Steel Research, Vol. 58 2002, pp 99-130. 